\title{
Laryngeal Disorders in Egyptian Patients with Gastroesophageal Reflux Disease
}

\author{
SABRY ABDEL FATAH EBRAЮM, M.D.*; SAYED GABER, M.D.*; \\ SAYED FAROUK MOHAMED, M.D.* and MOHAMED ABDEL MENAEM, M.D.** \\ The Departments of Tropical Medicine* and E.N.T**, Faculty of Medicine, Al-Azhar University, Cairo, Egypt
}

\begin{abstract}
Background: Gastroesophageal reflux disease (GERD) is chronic illness caused by reflux of gastric acidic contents back up into the esophagus causing wide range of symptoms. Laryngeal reflux is caused by A mechanism which seem identical to GERD some researchers think there is correlation between the prevalence of the two diseases.

Aim of Study: The study aimed to evaluate the prevalence of laryngeal reflux in cases of gastroesophageal reflux disease.

Methods: In this Prospective study evaluation of the prevalence of Laryngeal reflux symptom in cases of GERD was done in 200 patients by applying Reflux Finding Score (RFS) and Reflux Symptoms Index (RSI). They were divided into two groups Group-I; included 100 patients with Lartngeal reflux symptoms, Group-II; included 100 patients without Laryngeal reflux symptoms and this group was subdivided by laryngoscopic finding into Group-IIA; Laryngeal reflux free and Group-IIB; silent laryngeal reflux according to RFS.

Results: GERD was found in all $200(100 \%)$ patients included in the study Group I included 100 patients all of them had symptoms and signs of Laryngeal reflux, Group II included 100 patients didn't have symptoms of Laryngeal reflux of them 92 (92\%) patients (Group IIA) were found to be free of Laryngeal reflux signs and $8(8 \%)$ patients (Group IIB) were found to have signs of laryngeal reflux (silent laryngeal reflux).

Conclusion: Manifest Laryngeal reflux was found in 100 (50\%) of GERD patients, silent Laryngeal reflux was found in $8(8 \%)$ of GERD patients not complaining of Laryngeal reflux symptoms.
\end{abstract}

Key Words: Laryngopharyngeal reflux - Gastroesophageal reflux disease.

\section{Introduction}

GASTROESOPHAGEAL reflux disease (GERD) is a chronic disorder resulting from the retrograde flow of gastroduodenal contents into the esophagus.

Correspondence to: Dr. Sabry Abdel Fatah Ebrahim, The Department of Tropical Medicine, Al-Azhar University, Cairo, Egypt
Reduced LES pressure play a significant role in patients with moderate to severe disease, and exacerbated by obesity [1]. Other factors that decrease LES pressure and contribute to GERD are medications, lifestyle behaviors, and certain foods [2] Complications of GERD include esophageal ulcers, peptic esophageal strictures, Barrett's esophagus and esophageal adenocarcinoma [3]. The typical manifestations of GERD are heartburn, regurgitation, and dysphagia [4]. Atypical manifestations of GERD refer to symptoms that are extraesophageal including, ear, nose and throat $[\boldsymbol{s}$.

Laryngopharyngeal reflux (LPR) is the result of retrograde flow of gastric contents to the laryngophaynx. It account for $10 \%$ of patients presenting to otolaryngologist's office [6], mostly presenting with throat clearing (98\%), persisting cough (97\%), and hoarseness (95\%) [7]. Laryngoscopic signs of LPR are laryngeal irritation and inflammation but several findings are highly suggestive of LPR although not pathgnomonic [6].

\section{Aim of the work:}

The aim of this work was to evaluate the prevalence of laryngopharyngeal reflux in cases of gastroesophageal reflux disease by upper GI endoscopy and direct fibroptic laryngoscopy.

\section{Patients and Methods}

This study was conducted in the period between Sept 2015 and June 2016. Cases were selected from Gastrointestinal Endoscopy Unit, Faculty of Medicine, Al Azhar University. and enrolled 200 GERD patients devided into two groups: Group (I) i.e. Manifest LPR: Included 100 GERD patients complaining of LPR symptoms and were confirmed to have LPR by laryngoscope. Group (II) i.e. GERD without LPR symptoms: Included 100 patients. 
They were further subdivided into two subgroups according to their laryngoscopic findings; group IA: LPR-free whose laryngoscopic examination was free. group IIB: Silent LPR who were reported to have laryngoscopic findings. Adult patients from both genders and diagnosed endoscopically as GERD were included. Any patients with Alcohol intake, smoking, chronic tonsillitis and or chronic sinusitis, laryngopharengeal malignancy, allergy, taking NSAID, Ca-channels blockers, nitrates or theophylline or refused to participate in the study were excluded. The selected patients were subjected to written consent, full history and examination, routine lab investigations, upper G.I endoscopy and direct fiberoptic laryngoscope.

\section{Results}

The study included 200 patients with GERD subdivided into two groups in group I (Manifest LPR) the mean age of the patients was 40.4 years and there was females predominance $52 \%$ while males were $48 \%$ of the studied group, $60 \%$ were living in urban areas while $40 \%$ of the studied group lived in Rural areas. The mean BMI in group I was 32.9. As regard group II (Non-Manifest LPR) mean age was 39.8 , males were predominant by $52 \%$ while females were $52 \%$ of the studied group, $56 \%$ of the studied group lived in Urban areas while $44 \%$ lived in Rural areas. The mean BMI in groupie was 31.6 these data were statistically non significant between the two groups shown in Table (1). Heartburn and regurgitation were the most common symptoms 80 patients $(80 \%)$ and 72 patients (72\%) in group I and group II respectively and were statistically non significant between the two groups. Halitosis was in 60 patients $(60 \%)$ in group I and in 24 patients $(26.1 \%)$ in group II, dysphagia was in 56 patients (56\%) in group I and in 12 patients (12\%) in group II, nausea was in 48 patients (48\%) in group I and in 20 patients $(21.7 \%)$ in group II and apetite change was in 44 patients $(44 \%)$ in group I and in 28 patients $(30.4 \%)$ in group II. All were statistically significant between the studied groups as shown in Table (2). Upper endoscopic findings in the studied groups shows that GERD grade (A) was the commonest in all cases $(68 \%)$ and was more prevalent in group II $(76 \%)$, non of group II recorded grades CorD, gastritis was found in 124/200 (62\%) patients of the studied groups $72(72 \%)$ patients and $52(52 \%)$ patients in group I and II respectively, barette esophagus was found in $8(8 \%)$ patients all in group I as shown in Table (3). Of the 200 GERD patients group I: $100(50 \%)$ patients were having symptoms of LPR While group II: $100(50 \%)$ patients did not have symptoms of LPR of them 8 (8\%) were diagnosed to have silent LPR by laryngoscope as shown in Table (4). There were a predominance of laryngoscopic findings in males over females as shown in Fig. (1).

Table (1): Demographic features of the studied groups.

\begin{tabular}{lcccc}
\hline $\begin{array}{l}\text { Demographic } \\
\text { parameter }\end{array}$ & $\begin{array}{c}\text { Group I } \\
\text { Manifest LPR } \\
(\mathrm{n}=100)\end{array}$ & $\begin{array}{c}\text { Group II GERD } \\
\text { without LPR } \\
\text { symptoms }(\mathrm{n}=100)\end{array}$ & $\begin{array}{c}\text { Total } \\
(\mathrm{n}=200)\end{array}$ & $\begin{array}{c}p \text { - } \\
\text { value }\end{array}$ \\
\hline $\begin{array}{l}\text { Age: } \\
\text { Mean } \pm \text { SD }\end{array}$ & $40.4 \pm 12.9$ & $39.8 \pm 10.7$ & $40.1 \pm 11.8$ & 0.720 \\
$\begin{array}{l}\text { Sex: } \\
\text { Female no (\%) }\end{array}$ & $52(52 \%)$ & $48(48 \%)$ & $100(50 \%)$ & 0.571 \\
Male no (\%) & $48(48 \%)$ & $52(52 \%)$ & $100(50 \%)$ & \\
Residence: & & & & \\
Urban & $60(60 \%)$ & $56(56 \%)$ & $116(58 \%)$ & 0.566 \\
Rural & $40(40 \%)$ & $44(44 \%)$ & $84(42 \%)$ & \\
BMI: & & & & \\
Mean \pm SD & $32.9 \pm 5.6$ & $31.6 \pm 5.5$ & $31.8 \pm 5.55$ & 0.099 \\
Absolute figure & & & $148(74 \%)$ & 0.053 \\
$\quad>25$ & $80(80 \%)$ & $68(68 \%)$ & $52(26 \%)$ & \\
$\quad<25$ & $20(20 \%)$ & $32(32 \%)$ & & \\
\hline
\end{tabular}


Table (2): Gastrointestinal symptoms of the studied groups.

\begin{tabular}{lcccccc}
\hline & \multicolumn{1}{c}{ Group II GERD without LPR } & & Total \\
$\begin{array}{l}\text { Gastrointestinal } \\
\text { symptoms }\end{array}$ & $\begin{array}{c}\text { Group I } \\
\text { Manifest LPR } \\
(\mathrm{n}=100)\end{array}$ & $\begin{array}{c}\mathrm{A}= \\
\text { LPR-Free } \\
(\mathrm{n}=92)\end{array}$ & $\begin{array}{c}\mathrm{B}= \\
\text { Silent LPR } \\
(\mathrm{n}=8)\end{array}$ & $\begin{array}{c}\text { Total } \\
(\mathrm{n}=100)\end{array}$ & $\begin{array}{c}p- \\
\text { value } \\
\text { (I vs. II) }\end{array}$ \\
\hline Heart burn & $80(80 \%)$ & $68(73.9 \%)$ & $4(50 \%)$ & $72(72 \%)$ & $38(76 \%)$ & 0.185 \\
Regurgitation & $80(80 \%)$ & $68(73.9 \%)$ & $4(50 \%)$ & $72(72 \%)$ & $38(76 \%)$ & 0.185 \\
Halitosis & $60(60 \%)$ & $24(26.1 \%)$ & $0(0 \%)$ & $24(24 \%)$ & $21(42 \%)$ & $<0.001$ \\
Dysphagia & $56(56 \%)$ & $8(8.7 \%)$ & $4(50 \%)$ & $12(12 \%)$ & $17(34 \%)$ & $<0.001$ \\
Nausea & $48(48 \%)$ & $20(21.7 \%)$ & $0(0 \%)$ & $20(20 \%)$ & $17(34 \%)$ & $<0.001$ \\
Appetite change & $44(44 \%)$ & $28(30.4 \%)$ & $0(0 \%)$ & $28(28 \%)$ & $18(36 \%)$ & 0.018 \\
Vomiting & $36(36 \%)$ & $24(26.1 \%)$ & $0(0 \%)$ & $24(24 \%)$ & $15(30 \%)$ & 0.064 \\
Haematemesis & $8(8 \%)$ & $8(8.7 \%)$ & $0(0 \%)$ & $8(8 \%)$ & $4(8 \%)$ & 1.000 \\
\hline
\end{tabular}

Table (3): Gastroscopic examination of the studied groups.

\begin{tabular}{|c|c|c|c|c|c|c|}
\hline \multirow{2}{*}{$\begin{array}{l}\text { Gastroscopic } \\
\text { findings }\end{array}$} & \multirow{2}{*}{$\begin{array}{c}\text { Group I } \\
\text { Manifest LPR } \\
(\mathrm{n}=100)\end{array}$} & \multicolumn{3}{|c|}{$\begin{array}{l}\text { Group II GERD without LPR } \\
\text { symptoms }(n=25)\end{array}$} & \multirow{2}{*}{$\begin{array}{c}\text { Total } \\
(\mathrm{n}=200)\end{array}$} & \multirow{2}{*}{$\begin{array}{c}p \\
\text { value } \\
\text { (I vs. II) }\end{array}$} \\
\hline & & $\begin{array}{c}\mathrm{A}= \\
\text { LPR-Free } \\
(\mathrm{n}=92)\end{array}$ & $\begin{array}{c}B= \\
\text { Silent LPR } \\
(n=8)\end{array}$ & $\begin{array}{c}\text { Total } \\
(\mathrm{n}=100)\end{array}$ & & \\
\hline \multicolumn{7}{|l|}{ Esophagus: } \\
\hline \multicolumn{7}{|l|}{ GERD: } \\
\hline A & $60(60 \%)$ & $72(78.3 \%)$ & $4(50 \%)$ & $76(76 \%)$ & $136(68 \%)$ & 0.004 \\
\hline B & $32(32 \%)$ & $20(21.7 \%)$ & $4(50 \%)$ & $24(24 \%)$ & $56(28 \%)$ & \\
\hline$C \& D$ & $8 \quad(8 \%)$ & $\mathrm{O}(0 \%)$ & $0(0 \%)$ & $0(0 \%)$ & $8(4 \%)$ & \\
\hline Sliding hiatus hernia & $24(24 \%)$ & $16(17.3 \%)$ & $4(50 \%)$ & $20(20 \%)$ & $44(22 \%)$ & 0.494 \\
\hline Barrett's esophagus & $8 \quad(8 \%)$ & $\mathrm{O}(0 \%)$ & $0(0 \%)$ & $0(0 \%)$ & $8(4 \%)$ & 0.003 \\
\hline \multicolumn{7}{|l|}{ Stomach: } \\
\hline Gastritis & $72(72 \%)$ & $44(47.8 \%)$ & $8(100 \%)$ & $52(52 \%)$ & $124(62 \%)$ & 0.003 \\
\hline \multicolumn{7}{|l|}{ Duodenum: } \\
\hline Duodenitis & $36(36 \%)$ & $28(30.4 \%)$ & $8(100 \%)$ & $36(36 \%)$ & $72(36 \%)$ & 1.000 \\
\hline $\begin{array}{c}\text { Chronic active } \\
\text { duodenal. } \mathrm{U}\end{array}$ & $8 \quad(8 \%)$ & $4 \quad(4.3 \%)$ & $0(0 \%)$ & $4(4 \%)$ & $12(6 \%)$ & 0.233 \\
\hline
\end{tabular}

Tabble (4): Laryngoscopic examination of the studied groups.

\begin{tabular}{|c|c|c|c|c|c|c|}
\hline \multirow[b]{2}{*}{$\begin{array}{l}\text { Laryngoscopic } \\
\text { LPR signs }\end{array}$} & \multirow{2}{*}{$\begin{array}{c}\text { Group I } \\
\text { Manifest LPR } \\
(\mathrm{n}=100)\end{array}$} & \multicolumn{3}{|c|}{ Group II GERD without LPR } & \multirow[b]{2}{*}{$\begin{array}{c}\text { Total } \\
(\mathrm{n}=200)\end{array}$} & \multirow{2}{*}{$\begin{array}{c}p- \\
\text { value } \\
\text { (I vs. II) }\end{array}$} \\
\hline & & $\begin{array}{c}\mathrm{A}= \\
\text { LPR-Free } \\
(\mathrm{n}=92)\end{array}$ & $\begin{array}{c}B= \\
\text { Silent LPR } \\
(n=8)\end{array}$ & $\begin{array}{c}\text { Total } \\
(\mathrm{n}=100)\end{array}$ & & \\
\hline Vocal fold edema & $92(92 \%)$ & $0(0 \%)$ & $8(100 \%)$ & $8(8 \%)$ & $100(50 \%)$ & $<0.001$ \\
\hline Diffuse laryngeal edema & $84(84 \%)$ & $0(0 \%)$ & $8(100 \%)$ & $8(8 \%)$ & $92(46 \%)$ & $<0.001$ \\
\hline Erythema/Hyperemia & $80(80 \%)$ & $0(0 \%)$ & $8(100 \%)$ & $8(8 \%)$ & $88(44 \%)$ & $<0.001$ \\
\hline $\begin{array}{l}\text { Posterior commissure } \\
\text { hypertrophy }\end{array}$ & $76(76 \%)$ & $0(0 \%)$ & $4(50 \%)$ & $4(4 \%)$ & $80(40 \%)$ & $<0.001$ \\
\hline Thick endolaryngeal mucus & $52(52 \%)$ & $0(0 \%)$ & $4(50 \%)$ & $4(4 \%)$ & $56(28 \%)$ & $<0.001$ \\
\hline Granuloma & $32(32 \%)$ & $0(0 \%)$ & $0(0 \%)$ & $0(0 \%)$ & $32(16 \%)$ & $<0.001$ \\
\hline Pseudosulcus & $24(24 \%)$ & $0(0 \%)$ & $0(0 \%)$ & $0(0 \%)$ & $24(12 \%)$ & $<0.001$ \\
\hline Ventricular obliteration & $20(20 \%)$ & $0(0 \%)$ & $4(50 \%)$ & $4(4 \%)$ & $24(12 \%)$ & 0.001 \\
\hline RFS (mean) & 8.44 & 0 & 7 & 0.56 & - & 0.000 \\
\hline
\end{tabular}




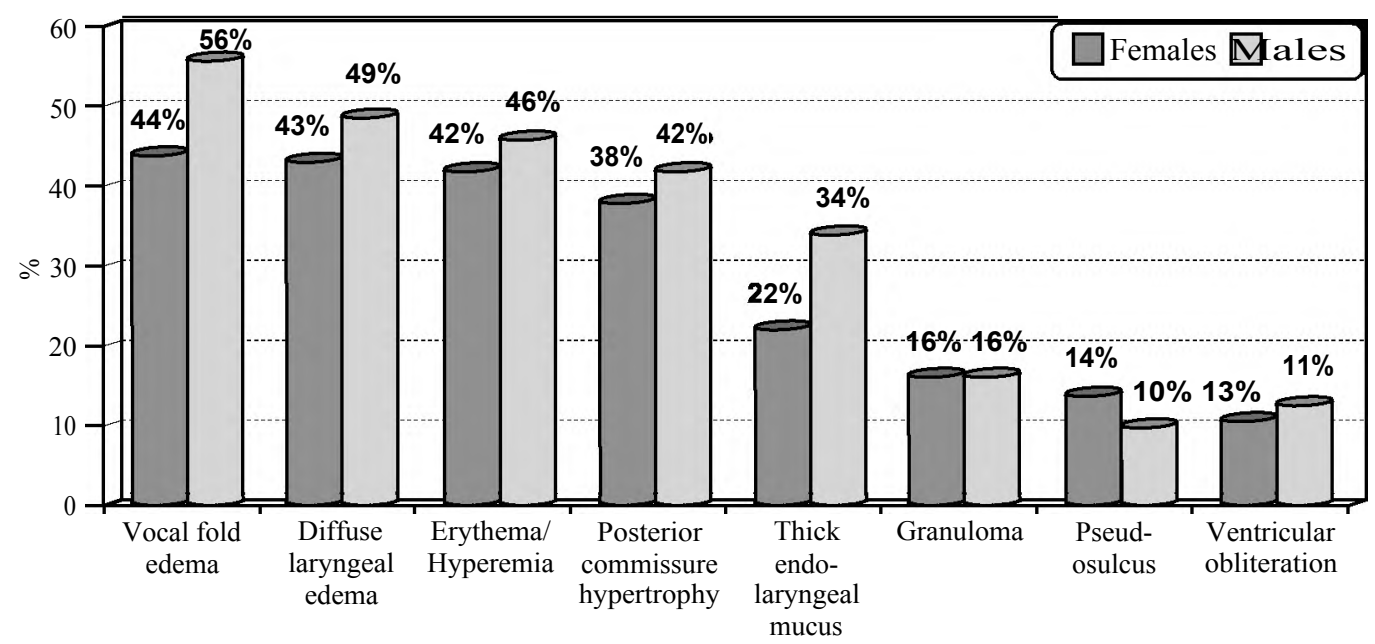

Fig. (1): Relation between gender in the studied patients and signs.

\section{Discussion}

The present study was done to evaluate the prevalence of laryngopharyngeal reflux in cases of gastroesophageal reflux disease included 200 patients diagnosed endoscopically to have GERD who were later classified according to LPR symptoms into: group $\mathrm{I}=100$ patients with manifest LPR and group $\mathrm{II}=100$ patients further subdivided into IIA=LPR-free patients and IIB=Silent LPR.

Neither sex nor age predilection was recorded in GERD. This is similar to Sandler and Everhart [8] and Kahrilas et al., [9]. It was detected in all range of age of the studied patients which matches with Kahrilas [10] and Merrouche et al., [11] who stated that GERD occurs in all age groups. But not matched with Johnson and Fennerty [1] who had suggested an association between advancing age and fewer reflux symptoms but the presence of more severe esophagitis.

That was also similar regarding LPR. Amirlak et al., [12] stated that there is no sex predilection in LPR. However, Koufman [7] mentioned that LPR was present more in females aged 57 years old. In the current study, 148 patients $(74 \%)$ were obese (mean $\mathrm{BMI}=31.8$ ) which confirms the role of obesity as a predisposing factor of GERD. This matches with Hampel et al., [13] who ascertained the role of obesity control in the correction of reflux. Regarding LPR, obesity was higher in group I than in group II ( 80 patients; $80 \%$, mean $\mathrm{BMI}=$ 32.9 and 68 patients; $68 \%$, mean $\mathrm{BMI}=31.6$ respectively). This agrees with Cooper et al., [14] who confirmed the role of obesity as an aggravating factor in GERD resulting in LPR. Heart burn and regurgitation were similarly the commonest symptoms complained by GERD cases (152 patients;
76\%). This matches with Johnson and Fennerty [1] who stated that they present in about $70-80 \%$ of cases of GERD. Regarding LPR, they were higher in group I than in group II (80 patients; $80 \%$ and 72 patients; $72 \%$ respectively, $p=0.185$ ).

Dysphagia was reported in approximately half cases of group I (56 patients; 56\%). This is similar to Chejtec [15]. Regarding LPR, it was significantly higher in group I than in group II (56 patients $56 \%$ and 12 patients $12 \%$ respectively, $p=0.01$ ). This agrees with Amirlak et al., [12] who concluded that LPR can lead to inflammation, edema, which can cause dysphagia with or without globus sensation.

Sliding hiatus hernia presented in 44 patients of all GERD cases $(22 \%)$. This ascertains the role of sliding hiatus hernia as a contributing factor in GERD. Van Herwaarden et al., [16] proved that patients with hiatus hernia had greater esophageal acid exposure and more reflux episodes than those without ( $7.6 \%$ vs. $3.3 \%$; $p<0.01$, and 3.1 vs. $1.8 / \mathrm{h}$; $p<0.001$ respectively). It was comparably detected in both groups ( 24 and 20 patients in groups I and II respectively) which matches with Kahrilas et al., [17] who ascertained that hiatus hernias may worsen the existing reflux and its symptoms in a minority of individuals resulting in LPR.

The commonest laryngoscopic findings were vocal fold and laryngeal oedema and erythema, all higher in group I than in group II $(92 \%, 84 \%$ and $80 \%$ versus $8 \%, 8 \%$ and $8 \%$ respectively). Meanwhile, 8 patients in group II (subgroup IIB), had these three laryngoscopic findings, therefore, they are defined as Silent LPR. This agrees with Remacle et al., [18] who mentioned that nonspecific signs of laryngeal irritation and inflammation are usually seen, but several findings are highly suggestive of 
LPR. Also, Reavis et al., [19] stated that LPR causes numerous chronic laryngeal disorders such as contact granuloma and ulcers, chronic laryngitis, subglottic stenosis, vocal polyps, laryngeal spasms, dysphonia and in the worst case scenario, laryngeal cancer. However, laryngoscopic signs are not pathognomonic, thickening, and, redness, and edema are common finding.

Whereas, the least prevalent signs was ventricular obliteration in both groups $(20 \%$ and $4 \%$ in groups I and II respectively). This is lower than that recorded by Koufman [20] i.e. 30\% of LPR cases. The advantage of this study is that it evaluated the prevalence of LPR in cases of GERD which was limited in the literature.

\section{Conclusion:}

From this study it was concluded that Manifest LPR in GERD patients constituted 50\%, complaining primarily from postnasal drip and throat clearing i.e. $96 \%$ each, while vocal fold and laryngeal edema and erythema were the most obvious signs i.e. $92 \%, 84 \%$, and $80 \%$ respectively. Silent LPR constituted $4 \%$ with GERD not complaining of any LPR symptoms. There is a significant direct proportional relationship between severity of GERD and both, the RSI and RFS.

\section{References}

1- JOHNSON D. and FENNERTY M.: "Heartburn severity underestimates erosive esophagitis severity in elderly patients with gastroesophageal reflux disease". Gastroenterology, 126: 660-664, 2004.

2- EL-SERAG H.: "Time trends of gastroesophageal reflux disease: A systematic review". Clin. Gastroenterol. Hepatol., 5 (1): 17-26, 2007.

3- DeVAULT K. and CASTELL D.: "Updated guidelines for the diagnosis and treatment of gastroesophageal reflux disease". Am. J. Gastroenterol., 100 (1): 190-200, 2005.

4- BUTTAR N. and FALK G.: "Pathogenesis of gastroesophageal reflux and Barrett's esophagus". Mayo. Clin. Proc., 76 (2): 226-34, 2001.

5- TASKER A., DETTMAR P., PANETTI M., et al.: "Is gastric reflux a cause of otitis media with effusion in children?" Laryngoscope, 112: 1930-1934, 2002.

6- FORD C.: "Evaluation and management of laryngopharyngeal reflux". JAMA, 294 (12): 1534-40, 2005.
7- KOUFMAN J., BELAFSKY P., BACH K., et al.: "Prevalence of esophagitis in patients with $\mathrm{pH}$-documented laryngopharyngeal reflux". Laryngoscope, 112: 16061609, 2002.

8- SANDLER R. and EVERHART S.: "The burden of selected digestive disease". Gastroenterology, 122: 1500$1511,2002$.

9- KAHRILAS P.J., SHAHEEN N.J. and VAEZI M.F.: American Gastroenterological Association Medical Position Statement on the management of gastroesophageal reflux disease. Gastroenterology, 135 (4): 1383-91, 2012.

10- KAHRILAS P.: "Gerd pathogenesis, pathophysiology and clinical manifestations". Cleve. Clin. J. Med., 70 (5): s419, 2003.

11-MERROUCHE M., SABATÉ J., JOUET P., et al.: "Gastroesophageal reflux and esophageal motility disorders in morbidly obese patients before and after bariatric surgery". Obes. Surg., 17 (7): 894-900, 2007.

12- AMIRLAK B., MUDD P.A. and SHAKER R.: Reflux Laryngitis. Am. J. Med., 29: 20-30, 2010.

13- HAMPEL H., ABRAHAM N. and EL-SERAG H.: "Metaanalysis: obesity and the risk for gastroesophageal reflux disease and its complications". Ann. Intern. Med., 143: 199-211, 2005.

14- COPPER M.P., SMIT C.F., STANOJCIC L.D., et al.: High incidence of laryngopharyngeal reflux in patients with head and neck cancer. The Laryngoscope, 110 (6): 1007-11, 2010.

15- CHEJTEC G.: "Gastroesophgeal reflux disease". US Gastroenterol., 1: 84-87, 2007.

16-VAN HERWAARDEN M.A., et al.: "Excess gastroesophageal reflux in patients with hiatus hernia is caused by mechanisms other than transient LES relaxation". Gastroenterology, 119 (6): 1439-46, 2000.

17- KAHRILAS P., QUIGLEY E., CASTELL D., et al.: "The effects of tegaserod (HTF 919) on oesophageal acid exposure in gastro-oesophageal reflux disease". Aliment. Pharmacol. Ther., 141503-1509, 2000.

18- REMACLE M., et al.: "Diagnosis and management of laryngopharyngeal reflux disease". Curr. Opin. Otolaryngol. Head Neck Surg., 14 (3): 143-9, 2006.

19- REAVIS K., MORRIS C., GOPAL D., et al.: "Laryngopharyngeal reflux symptoms better predict the presence of esophageal adenocarcinoma than typical gastroesophageal reflux symptoms". Ann. Surg., 239 (6): 849-856, 2004.

20- KOUFMAN J.A.: Laryngopharyngeal reflux is different from classic gastroesophageal reflux disease. Ear, Nose \& Throat Journal, 81 (9): 7, 2011. 


\section{التفيرات الحنجرية فى المرضى المصريين المصابين

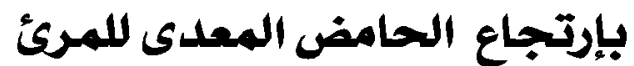

الإرتجاع المعدى المرينى هو مرض مزمن فى الجهاز الهضمى، يحدث عندما يتدفق حمض المعدة، أو أحياناً الصفراء إلى المرىئ. وهذا

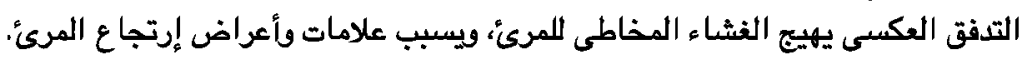

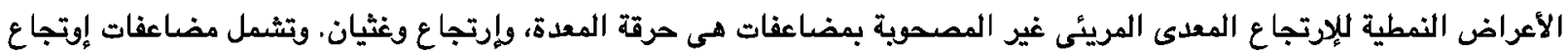

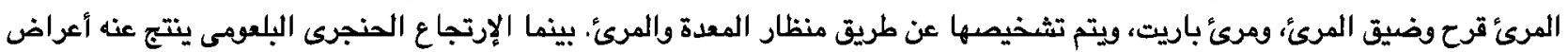

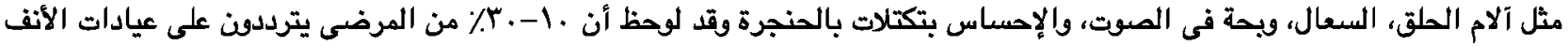
والأذن والحنجرة يعانون من هذا المرضع.

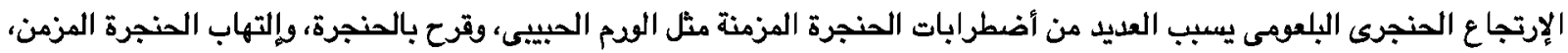

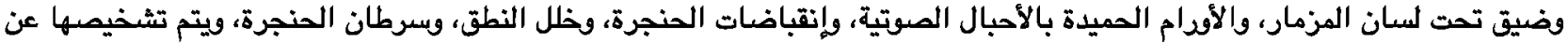
طريق منظار الحنجرة.

والهدف من هذا العمل هو تقييم الإرتجاع الحنجرى البلعومى فى حالات إرتجاع المرىئ وإيجاد حالات الإرتجاع الحنجرى البلعومى الصامت



وقد أجريت هذه الدراسة على . . ب مريض لإرتجاع المرئ، وقد تمت دراسة الإرتجاع الحنجرى البلعومى عن طريق تطبيق مؤشر علامات

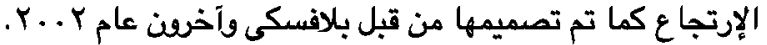

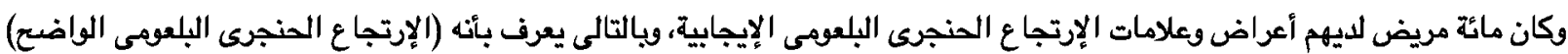

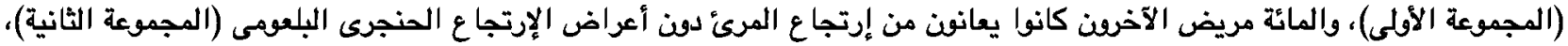

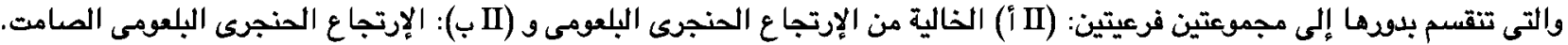

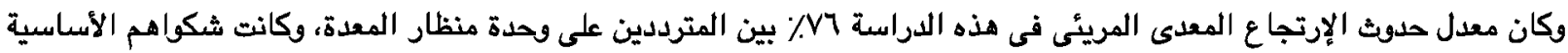

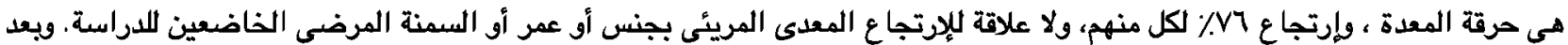

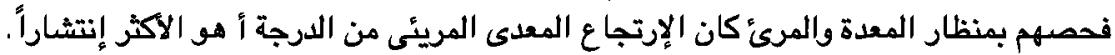

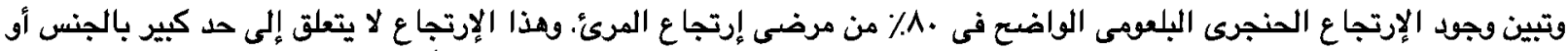

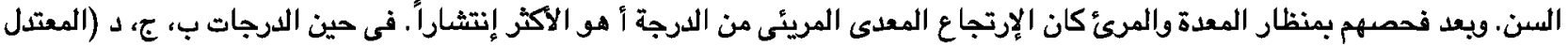

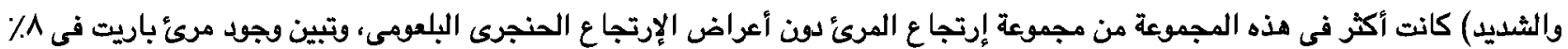
من المرضى فى هذه المجموعة.

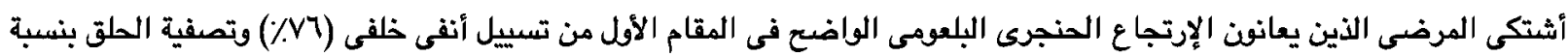

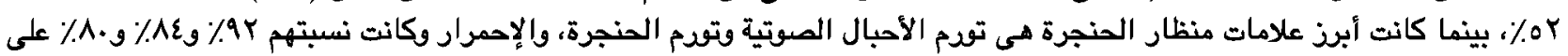

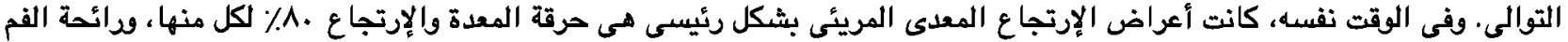

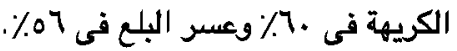





وقد لوحظ أن شدة الإرتجاع المعدى المريئى كانت متناسبة إلى حد كبير مع كل من مؤشر علامات الإرتجاع ومؤشر أعراض الإرتجاع.

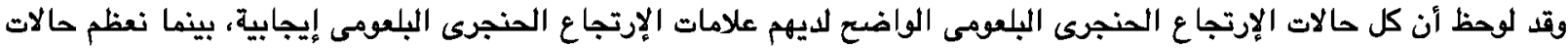

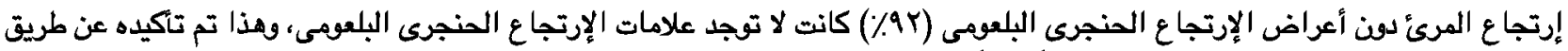

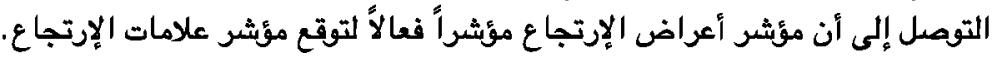

